\title{
Widespread Triggering of Nonvolcanic Tremor in California
}

Joan Gomberg, ${ }^{1 *}$ Justin L. Rubinstein, ${ }^{2}$ Zhigang Peng, ${ }^{3}$ Kenneth C. Creager, ${ }^{2}$ John E. Vidale, ${ }^{2}$ Paul Bodin ${ }^{2}$

$\mathrm{T}$ remor away from volcanoes (1), termed nonvolcanic tremor, reflects a fault slip regime different than that of earthquakes. Relative to radiation from earthquakes, tremor signals have longer durations, have fewer or no abrupt wave onsets, and are depleted in high frequencies. Tremor has almost exclusively been found in subduction zones: Cascadia, southwestern Japan, Mexico, Costa Rica, and Alaska; there is only one study documenting tremor outside a subduction-dominated region, on the strike-slip San Andreas Fault in Parkfield, California (2). In Japan and Cascadia, nonvolcanic tremor has been shown to occur concurrently with slippage across the interface between subducting and overlying plates, both lasting for days to months (3). The pace and amount of slip are much smaller than those during earthquakes that rupture comparably sized fault areas, and thus these slow events radiate less seismic energy. The physical relation between the slow slip and tremor generation remains speculative. Recent studies in subduction zones

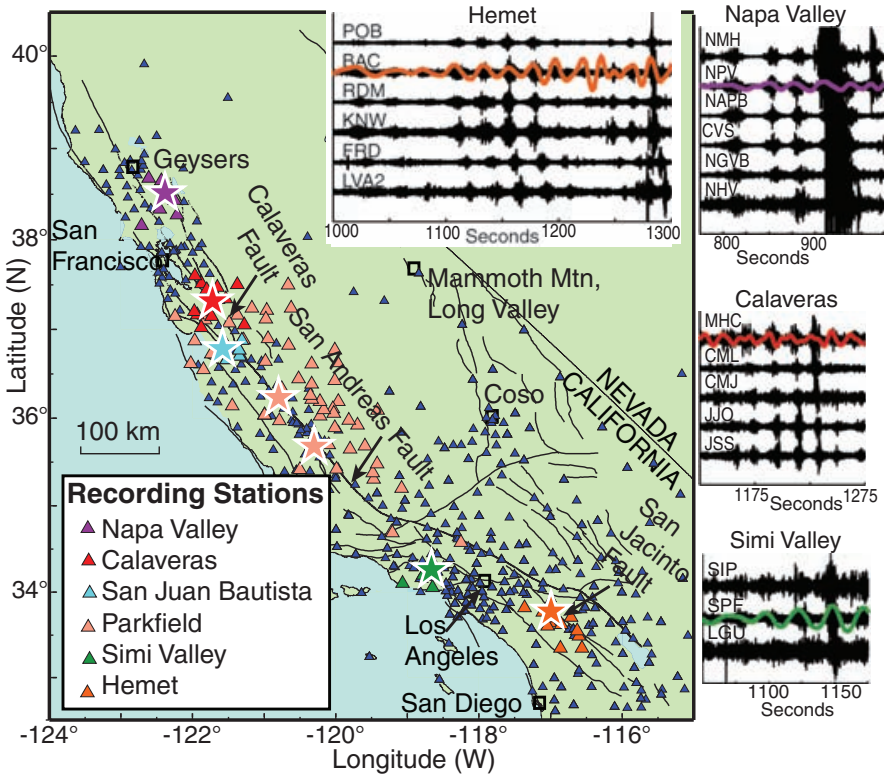

Fig. 1. Map of the locations of tremor sources [stars (5)], stations that recorded signals from each tremor source (triangles color coded to the respective sources, see legend), stations that showed no tremor (dark blue triangles), and major faults (black lines). (Insets) Examples of the tremor signals associated with four regions where single tremor sources are identified. The Denali surface waves have been filtered out to highlight the tremor (black seismograms), and colored traces show the transverse component of the surface waves from Denali at one unfiltered broadband station in each region, noting that the amplitudes on the radial and vertical components do not differ significantly. Depending on the tremor site, we observed tremor triggering by both Love and Rayleigh waves. The last large bursts in the Hemet and Napa Valley signals are characteristic of nearby earthquakes. Each seismogram has been scaled to make the tremor easily identifiable, times are referenced to the Denali earthquake origin time, and recording stations are labeled.

have identified short bursts of tremor with the same measurable characteristics as those associated with slow slip, but triggered by the strong shaking of distant earthquakes (4). Because nonvolcanic tremor is preferentially observed in subduction zones, nearly all causative mechanisms proposed appeal to conditions expected in them. We show that the conditions required for its generation must exist in a wider variety of tectonic environments by presenting observations of nonvolcanic tremor at seven sites along the transform plate boundary in California triggered by the 20027.8 moment magnitude Denali Fault, Alaska, earthquake. of the passing surface waves. This energy is not associated with nearby earthquakes or with the Denali earthquake itself. We identified tremor from seven sources that we located by using tremor envelopes as input to a grid-search algorithm (5). These locations range from the desert southeast of Los Angeles to Napa Valley in the north (Fig. 1).

Although the observed tremor bursts span a large transect of California, five sources locate close to or on dominant strike-slip faults: the San Andreas, the San Jacinto, and the Calaveras faults. The Simi Valley and Napa Valley sources are likely on more minor faults. Some models of tremor associated with slow aseismic slip in subduction zones invoke frictional behaviors expected in regions transitional between where the fault is locked and earthquakes occur and where it is slipping freely below (6). Such transition zones also must exist at shallow depths both below the top few $\mathrm{km}$ of fault segments known to creep continuously and laterally between locked segments and those that creep for most or all of their depth. The distribution of these various behaviors is known for most faults in California. However, we find no clear correlation between where the faults are creeping, locked, or transitional and where tremor occurs.

Many studies have speculated that aseismic slip and tremor are related to the release of fluids from dehydration of the subducting plate (1). Given this expected correlation between fluids and nonvolcanic tremor, we examined the data from stations close to the Coso and Geysers geothermal fields. We identified signals of many triggered earthquakes, but no tremor was apparent. These findings agree with previous work on triggered earthquakes at these sites and at the hydrothermal regions in Long Valley Caldera and Mammoth Mountain (7). The lack of triggered tremor in these geothermal regions implies that high fluid pressure and/or temperatures, although they may be necessary, are not alone sufficient to produce tremor.

In interpreting our results, it is important to note where we found triggered tremor as well as where we did not. The paucity of triggered tremor in hydrothermal regions and its lack of correlation with local, ambient slip behavior suggest that very specific conditions (e.g., temperature, pressure, fluid content, and frictional properties) control where tremor and earthquakes occur. The wide geographic extent of the triggered tremor indicates that it is more common than previously recognized and that the necessary conditions exist in a wide range of tectonic environments.

\section{References}

1. K. Obara, Science 296, 1679 (2002).

2. R. M. Nadeau, D. Dolenc, Science 307, 389 (2005); published online 9 December 2004

(10.1126/science.1107142).

3. G. Rogers, H. Dragert, Science 300, 1942 (2003); published online 8 May 2003 (10.1126/science.1084783).

4. J. L. Rubinstein et al., Nature 448, 579 (2007).

5. Materials and methods are available as supporting material on Science Online.

6. Y. Liu, J. R. Rice, J. Geophys. Res. 110, 10.1029/2004JB003424 (2005).

7. S. Prejean et al., Bull. Seismol. Soc. Am. 94, S348 (2004). Supporting Online Material www.sciencemag.org/cgi/content/full/1149164/DC1 Materials and Methods

13 August 2007; accepted 17 October 2007

Published online 22 November 2007;

10.1126/science. 1149164

Include this information when citing this paper.

${ }^{1}$ U.S. Geological Survey, Box 351310, Seattle, WA 98195 USA. ${ }^{2}$ Department of Earth and Space Science, University of Washington, Box 351310, Seattle, WA 98195, USA. ${ }^{3}$ School of Earth and Atmospheric Sciences, Georgia Institute of Technology, 311 Ferst Drive, Atlanta, GA 30332-0340, USA.

*To whom correspondence should be addressed. E-mail: gomberg@usgs.gov 